\title{
OPTIMASI SISTEM CERDAS PADA PENGERING TANAMAN OBAT BERBASIS INTERNET OF THING DENGAN MEMANFAATKAN SUMBER ENERGI TERBARUKAN
}

\author{
Heriansyah $^{1}$, Swadexi Istiqphara ${ }^{2}$, Nur Adliani $^{3}$ \\ ${ }^{1,2}$ Program Studi Teknik Elektro, Institut Teknologi Sumatera Lampung, Indonesia \\ ${ }^{2}$ Program Studi Farmasi, Institut Teknologi Sumatera, Indonesia \\ ${ }^{1}$ herieitera.ac.id \\ ${ }^{1}$ swadexi.istiqpharadel.itera.ac.id \\ ${ }^{3}$ nur.adlianiefa.itera.ac.id
}

Intisari - Penelitian ini membahas tentang optimasi sistem cerdas yang akan diterapkan pada sistem pengering tanaman obat berbasis internet of thing dan memanfaatkan sumber energi terbarukan. Pemilihan metode sistem kendali menjadi sangat penting karena sumber daya yang akan digunakan pada sistem pengering ini adalah energi terbarukan yang memiliki batasan waktu. Pada sistem pengering ini juga digunakan Internet of thing untuk memantau dan mengatur suhu ruangan kabinet. Untuk mendapatkan performa sistem yang optimal, maka diusulkan metode Smart Fuzzy sebagai sistem kendali cerdas untuk mengendalikan suhu ruangan kabinet agar mencapai target yang diinginkan pengguna. Pengujian metode sistem kendali dilakukan dengan menggunakan simulasi pada perangkat lunak komputer. Metode Smart Fuzzy yang diusulkan akan dibandingkan dengan metode PID untuk membuktikan efektifitas dari metode yang diusulkan. Metode Smart Fuzzy merupakan metode kendali yang menggunakan logika Fuzzy untuk mengambil keputusan besar kecilnya sinyal masukan sebuah sistem. Metode ini menggunakan basis aturan yang diperoleh dari pengetahuan manusia. Hasil simulasi komputer yang diperoleh menunjukan metode Smart Fuzzy memiliki performa lebih baik dibandingkan metode PID. Hal ini terlihat dari osilasi pada luaran dengan menggunakan metode Smart Fuzzy lebih kecil dibandingkan dengan menggunakan metode PID.

Kata kunci: Smart Fuzzy, basis aturan, logika, tanaman obat, temperatur ruang

Abstract - This research discusses the optimization of an intelligent system that will be applied to the drying system of medicinal plants based on the internet of things and utilizing renewable energy sources. The control system method is becoming very important, given that the resources to be used in this drying system are renewable energy with a time limit. This drying system also uses the Internet of things to monitor and regulate the temperature of the cabinet room. In order to achieve optimal system performance, an intelligent control system method is proposed to control the temperature of the cabinet room in order to achieve the desired target of the user by using the Smart Fuzzy method. The control system method will be tested on a computer using software simulations. The proposed Smart Fuzzy method will be compared with the PID method to demonstrate the effectiveness of the proposed method. Smart Fuzzy is a control method that uses Fuzzy logic to make decisions about the size of the input signal system. This method uses a rule-based approach derived from human knowledge. The results obtained from the software simulation show that the Smart Fuzzy method has better performance than the PID method. From the output oscillation, it can be seen that using the Smart Fuzzy method is smaller than using the PID method.

Keywords: Smart Fuzzy, rule base, logic, medicinal plants, room temperature 


\section{PENDAHULUAN}

Kesadaran masyarakat akan pentingnya obat herbal saat ini semakin meningkat sehingga menjadi gaya hidup yang sangat diminati. Gaya hidup ini membawa masyarakat kembali memanfaatkan bahan alam, termasuk pengobatan dengan tanaman berkhasiat obat [1]. Kesadaran ini dipicu oleh pemahaman masyarakat tentang efek samping positif yang diberikan oleh obat herbal dibandingkan dengan obat modern yang memiliki banyak efek samping negatif.

Hasil penelitian menunjukkan bahwa kurang lebih $50 \%$ penduduk Indonesia mengkonsumsi jamu sebagai alternatif obat modern maupun suplemen dalam menjaga kesehatan tubuh. Dari hasil tersebut, 55,3\% penduduk indonesia mengkonsumsi jamu dalam bentuk cairan dan sisanya mengkonsumsi jamu dalam bentuk serbuk [2]. Peningkatan jumlah penduduk yang sadar akan pentingnya obat herbal telah mendukung pertumbuhan industri obat herbal dalam meningkatkan kualitas obat yang mereka hasilkan.

Teknik penanganan pascapanen yang kurang tepat menimbulkan permasalahan dalam menghasilkan simplisia yang berkualitas. Teknik penangan pascapanen sendiri terdiri dari proses sortasi, pencucian, penirisan, perajangan, pengeringan, dan pengolahan menjadi berbagai macam produk farmasi yang sesuai dengan standar Badan Pengawas Obat dan Makanan (BPOM). Salah satu teknik pasca panen yang sangat penting dalam menghasilkan simplisia yang baik adalah teknik pengeringan.

Sistem pengeringan alami yang ada saat ini membutuhkan waktu yang cukup lama untuk mengurangi kadar air dalam tanaman obat karena hanya mengandalkan sinar matahari langsung dalam proses pengeringan. Pergantian siang dan malam serta cuaca yang berubahubah sepanjang tahun menjadi kendala dalam sistem pengeringan tradisional. Pada musim hujan, kadar air yang ada di dalam tanaman obat dapat meningkat sehingga tanaman tersebut berpotensi menjadi media tumbuh jamur, di samping itu proses pengeringan yang dilakukan di ruang terbuka di mana tanaman obat terpapar sinar matahari langsung dapat menyebabkan tanaman obat tersebut terlalu kering sehingga menghasilkan produk berkualitas rendah.

Pada penelitian sebelumnya, kami telah merancang sistem pengering tanaman obat berbasis mikrokontroler dengan menggunakan metode kontrol PID dalam mengatur suhu ruangan yang diinginkan [3]. Berdasarkan hasil uji yang dilakukan, suhu ruangan yang dihasilkan belum optimal sehingga penggunaan daya cadangan yang dihasilkan oleh solar panel menjadi lebih boros. Penggunaan solar panel dimaksudkan untuk mengaktifkan elemen pemanas atau exhaust fan yang sudah kita pasang pada alat pengering. Jika suhu yang dihasilkan oleh alat pengering lebih kecil dari ambang batas yang telah ditetapkan, maka solar panel berfungsi untuk mengaktifkan elemen pemanas sedangkan exhaust fan diaktifkan ketika suhu lebih besar dari nilai ambang batas.

Kurang optimalnya pengendalian suhu ruangan kabinet mendorong kami untuk mencari metode kontrol lain yang lebih optimal dengan memanfaatkan simulasi komputer. Dengan simulasi tersebut kita dapat melakukan simulasi terkait metode kontrol lain yang lebih optimal dalam mengendalikan suhu di dalam ruang kabinet.

Metode kontrol yang akan disimulasikan dalam penelitian ini adalah metode Smart Fuzzy. Hasil simulasi ini selanjutnya akan dibandingkan dengan hasil simulasi menggunakan metode kontrol PID. Berdasarkan hasil tersebut maka dapat disimpulkan jenis metode kontrol apa yang lebih cocok untuk diterapkan pada alat pengering tanaman obat yang telah dirancang sebelumnya.

\section{PENELITIAN TERKAIT}

Penelitian terkait sistem kendali suhu ruang sudah banyak dilakukan sebelumnya. Penulis [4] membahas tentang perancangan dan simulasi sistem kendali temperatur ruang otomatis pada menggunakan mikrokontroler untuk mengendalikan suhu ruang dengan menyalakan pemanas atau fan untuk 
mendinginkan. Selanjutnya penelitian [5] juga membahas terkait pengendalian suhu ruang dengan menggunakan metode PID disturbance observer. Pada metode ini disturbance observer digunakan untuk mengestimasi gangguan suhu dari luar yang mempengaruhi suhu ruang tersebut. Pengujian dilakukan dengan membandingkan metode PID dan metode PID-DOB. Hasil yang diperoleh menunjukan metode PID-DOB memberikan hasil yang lebih baik dalam mengendalikan suhu ruang meskipun terdapat gangguan dari suhu luar ruangan. Penulis [6] melakukan penelitian untuk menjaga suhu dan kelembaban ruang server dengan menggunakan metode Fuzzy Logic berbasis mikrokontroler. Hasil yang diperoleh metode Fuzzy Logic mampu mengendalikan suhu ruang server dengan baik. Fuzzy Logic juga diterapakan pada pengendalian suhu ruang [7]. Metode Fuzzy Logic ini dibandingkan dengan menggunakan PID dan hasil yang diperoleh menunjukan metode Fuzzy Logic lebih baik daripada PID. Beberapa penelitian juga menunjukan metode Fuzzy Logic efektif mengendalikan suhu, termasuk pada suhu reaktor [8]. Metode Fuzzy juga banyak digunakan untuk proses pengendalian suhu, termasuk pada pemanas air [9]. Metode Fuzzy selain digunakan sebagai pengendali utama, dapat juga digunakan untuk meningkatkan performa kendali PID yang dikombinasikan dengan Genetic Algorithm untuk mengendalikan temperatur pada stired tank seperti yang dilakukan pada [10].

\section{MODEL MATEMATIKA}

Pada penelitian sebelumnya telah dirancang sistem kabinet pengering yang terdiri dari pengumpul panas dan pembuang panas. Adapun pengumpul panas diperoleh dari elemen pemanas dan matahari. Kabinet pengering ini berukuran lebar $50 \mathrm{~cm}$, panjang $60 \mathrm{~cm}$ dan tinggi keseluruhan $120 \mathrm{~cm}$ seperti yang ditunjukkan oleh gambar 1 .

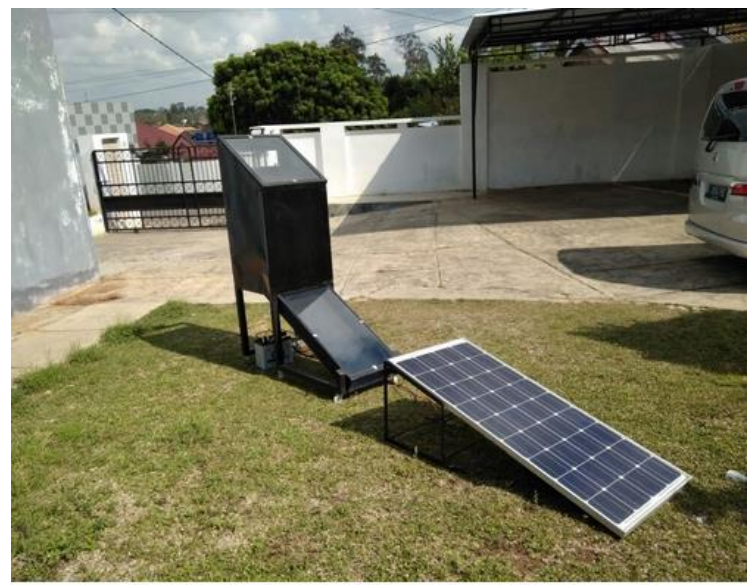

Gambar 1. Kabinet pengering dan solar panel

Elemen pemanas terletak dibagian bawah dan sensor suhu berada pada rak bagian tengah. Sistem ini memiliki 3 rak dengan tinggi masing-masing $20 \mathrm{~cm}$. Pada bagian bawah pengumpul panas, terdapat ventilasi yang berfungsi sebagai tempat masuk udara dari bawah. Kontroler dan komponen lainnya tepat berada dibagian bawah kabinet.

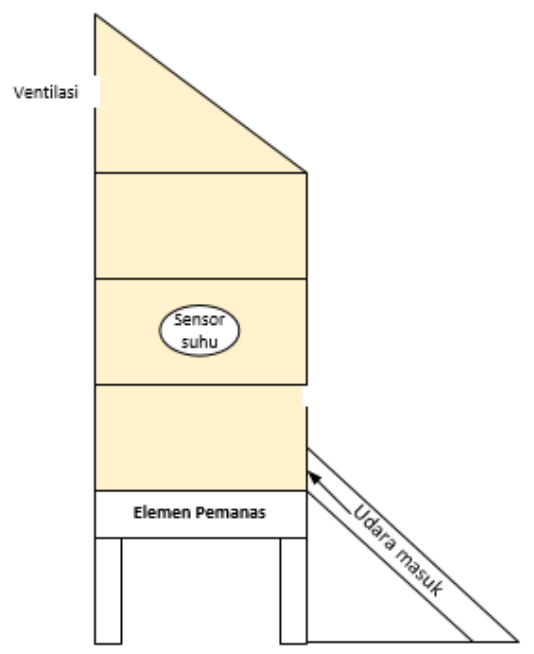

Gambar 2. Desain kabinet pengering

Pada penelitian ini dilakukan pemodelan untuk memodelkan sistem ke persamaan matematika agar dapat digunakan sebagai plant pada perancangan sistem kendali di simulasi komputer. Adapun pemodelan matematika dari sistem yang digambarkan pada gambar 2 adalah seperti yang dinyatakan pada persamaan berikut:

$Q_{\text {gain }}=\mathrm{m}_{\text {pemanas }} C_{\text {udara }}\left(T_{\text {pemanas }}-\mathrm{T}_{\text {cab }}\right)$ 
kecepatan transfer energi panas dari elemen pemanas dinyatakan dengan

$d \frac{Q_{\text {gain }}}{\mathrm{dt}}=\mathrm{d} \frac{m_{\text {pemanas }}}{\mathrm{dt}} C_{\text {udara }}\left(T_{\text {pemanas }}-\mathrm{T}_{\text {cab }}\right)$

sedangkan untuk energi panas yang terbuang akibat keluar melalui ventilasi dinyatakan dengan

$Q_{\text {hilang }}=\frac{\mathrm{kA}\left(T_{\text {ruang }}-\mathrm{T}_{\text {luar }}\right)}{D} t$

kecepatan transfer energi panas yang hilang terbuang dinyatakan dengan

$d \frac{Q_{\text {hilang }}}{\mathrm{dt}}=\mathrm{kA} \frac{\left(T_{\text {ruang }}-\mathrm{T}_{\text {luar }}\right)}{D}$

dari persamaan 1-4 maka persamaan perubahan suhu ruang kabinet dinyatakan dengan

$d \frac{T_{\text {ruang }}}{\mathrm{dt}}=\frac{1}{m_{\text {ruang }} c_{\text {udara }}}\left(d \frac{Q_{\text {gain }}}{\mathrm{dt}}-\mathrm{d} \frac{Q_{\text {hilang }}}{\mathrm{dt}}\right)$

di mana:

$\mathrm{Q}=$ energi yang berpindah (joule)

$\mathrm{A}=$ luas ruangan bagian dalam (meter)

$\mathrm{k}=$ konduktivitas termal (joule/meter.jam. derajat)

$\mathrm{m}=$ massa udara $(\mathrm{kg})$

$\mathrm{T}=$ suhu (derajat)

$\mathrm{C}=$ Kapasitas Panas (joule/kilogram derajat)

Metode sistem kendali yang diusulkan pada penelitian ini adalah metode kendali Smart Fuzzy, metode Smart Fuzzy menggunakan pengetahuan ahli (knowledge expert) sebagai basis aturan. Sehingga metode fuzzy dapat bekerja untuk mengendalikan sistem secara otomatis seperti cara manusia berpikir.

Metode kendali Smart Fuzzy menggunakan kendali Proporsional dan Derivative untuk mengolah sinyal error antara target dengan suhu aktual yang didefinisikan sebagai berikut:

$e=s p-a v$

di mana:

$\mathrm{sp}=$ setpoint atau target

av = aktual value

untuk formulasi PID yang akan digunakan adalah
$P I D=K_{p} e+K_{d} \frac{d e}{d t}+K_{i} \int e d t$

dimana:

$\mathrm{Kp}:$ Kontroler proportional

$\mathrm{Kd}$ : Kontroler integral

$\mathrm{Ki}$ : Kontroler derivative

Kemudian sinyal proporsional error dan delta error akan di Fuzzifikasi yaitu merubah sinyal error dan sinyal delta error menjadi keanggotaan fuzzy input, keanggotaan fuzzy dari error dan delta error kemudian diolah oleh inferensi fuzzy, inferensi Fuzzy merupakan proses pengambilan keputusan berdasarkan basis aturan (rule base) yang didefinisikan pada tabel 1 .

Tabel 1. Basis aturan pada Smart Fuzzy

\begin{tabular}{|c|l|l|l|l|l|}
\hline elde & PB & PS & \multicolumn{1}{|c|}{ NS } & NB \\
\hline PB & NB & NB & NS & NS & Z \\
\hline PS & NB & NS & NS & Z & PS \\
\hline $\mathbf{Z}$ & NS & NS & Z & PS & PS \\
\hline NS & NS & Z & PS & PS & PB \\
\hline NB & Z & PS & PS & PB & PB \\
\hline
\end{tabular}

di mana:

PB : Positif Big

PS : Positif Small

$\mathrm{Z} \quad$ : Zero

NS : Negatif Small

NB : Negatif Big

Proses pengambilan keputusan pada inferensi rule akan memberikan luaran berupa keanggotaan fuzzy output yang akan diumpankan ke bagian defuzzifikasi. Pada bagian defuzzifikasi, nilai-nilai keanggotaan Fuzzy Output sebagai hasil luaran inferensi rule akan diubah ke nilai sinyal kontrol yang akan diinputkan ke sistem tanaman obat. Adapun blok diagram dari proses Fuzzy dinyatakan pada blok diagram berikut ini: 


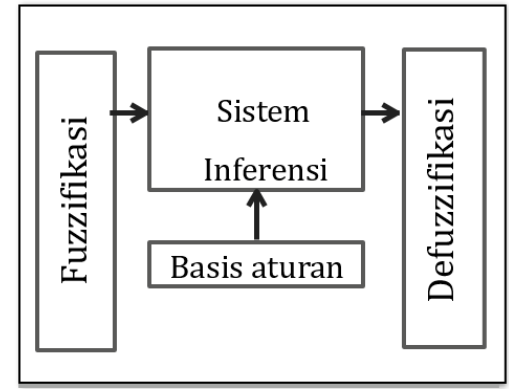

Gambar 3. Blok diagram sistem Fuzzy

Adapun fungsi keanggotaan Fuzzy yang digunakan adalah segitiga seperti pada gambar berikut ini:

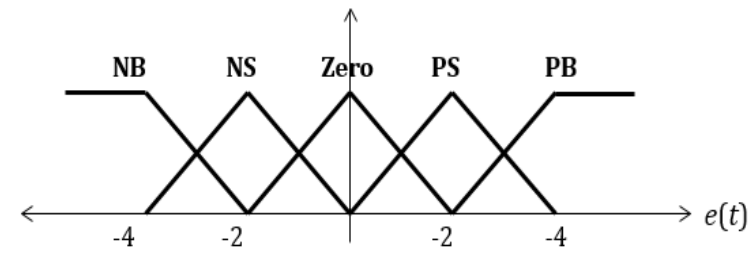

Gambar 4. Fungsi keanggotaan Fuzzy Input Error

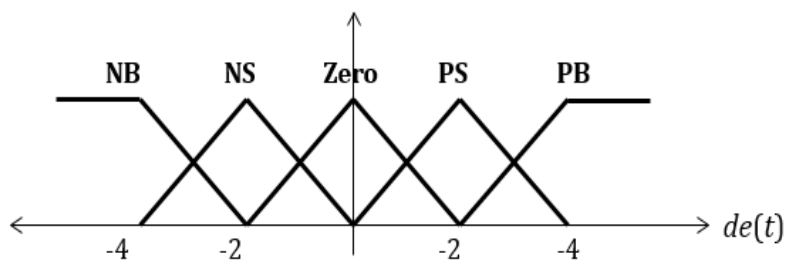

Gambar 5. Fungsi keanggotaan Fuzzy Input Delta Error

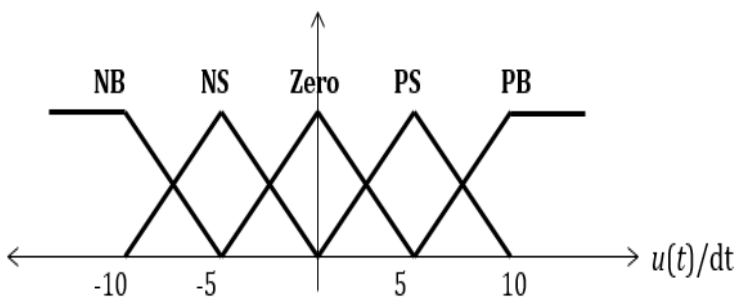

Gambar 6. Fungsi keanggotaan Fuzzy Output

Untuk proses Defuzifikasi, formula yang digunakan adalah formulasi center of gravity yang dinyatakan pada persamaan (7)

$Q_{\text {hilang }}=\frac{\mathrm{kA}\left(T_{\text {ruang }}-T_{\text {luar }}\right)}{D} t$

Secara keseluruhan blok diagram sistem kendali temperatur ruang kabinet ini ditunjukkan oleh gambar 7 .

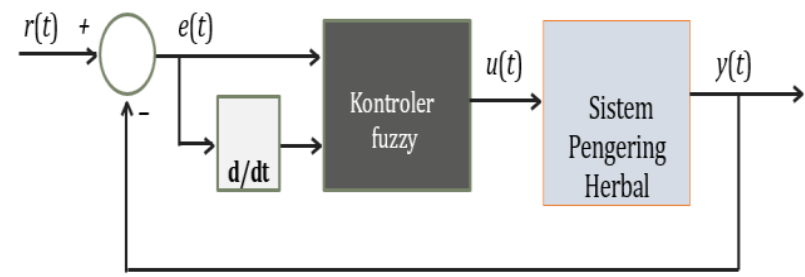

Gambar 7. Blok Diagram sistem Kendali

IV. HASIL DAN PEMBAHASAN

Untuk melihat efektifitas metode yang diusulkan, sistem kendali yang diusulkan diuji dengan menggunakan simulasi pada komputer. Hal ini bertujuan untuk memiimalisir kerusakan yang terjadi sebelum alat benarbenar diimplementasikan. Pengujian dilakukan dengan membandingkan metode yang diusulkan dengan metode yang sudah pernah diuji pada penelitian sebelumnya yaitu dengan menggunakan kontroler PID. Adapun parameter yang digunakan pada sistem kendali adalah sebagai berikut :

\begin{tabular}{|l|l|}
\hline Variabel & Nilai \\
\hline $\mathrm{Kp}$ & $1,2.5$ \\
\hline $\mathrm{Kd}$ & 2.5 \\
\hline $\mathrm{Ki}$ & 1 \\
\hline
\end{tabular}

Pada pengujian dengan menggunakan metode kendali proporsional, dapat dilihat bahwa hasil yang diperoleh mengalami osilasi sebesar $\pm 2^{\circ} \mathrm{C}$. Hal ini menunjukan bahwa dengan metode ini, sistem pengering tanaman obat dapat mencapai suhu yang diinginkan namun tidak dapat menjaga suhu tetap pada nilai yang telah ditetapkan dengan osilasi kurang dari $1^{\circ} \mathrm{C}$. Hal ini sangat penting mengingat suhu yang stabil pada ruang kabinet akan mempercepat pengeringan tanaman herbal sehingga dapat menghemat daya yang digunakan. 


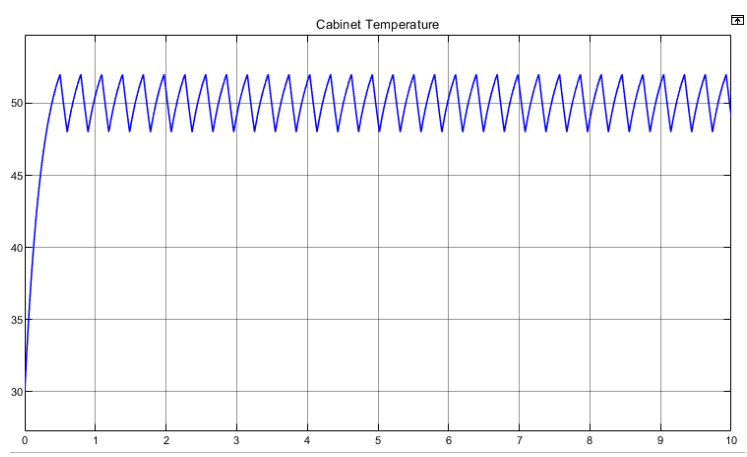

Gambar 8. Hasil simulasi dengan menggunakan metode kendali proporsional.

Sedangkan dengan menggunakan sistem kendali Proporsional Derivative (PD) terlihat osilasi yang terjadi pada sistem menjadi lebih kecil, namun sistem menjadi lebih lambat dalam mencapai target suhu yang telah ditetapkan sebelumnya. Untuk mencapai nilai yang telah ditetapkan, waktu yang dibutuhkan sekitar 2 menit.

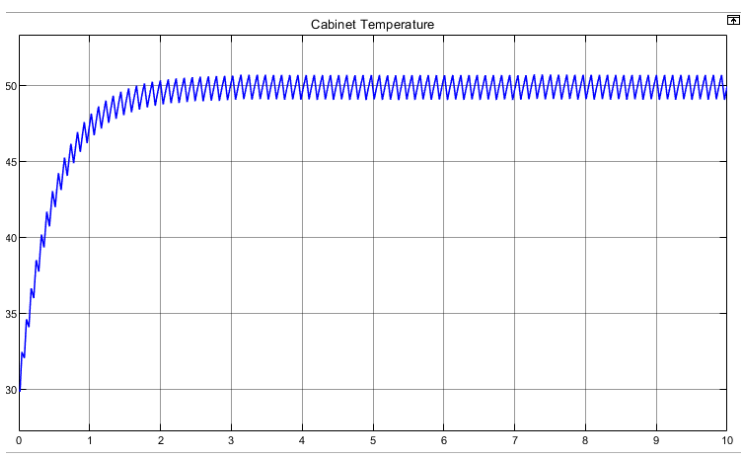

Gambar 9. Hasil simulasi dengan menggunakan metode kendali Proporsional Derivative (PD)

Pengujian metode selanjutnya adalah dengan menggunakan kontroler PID. Hasil pengujian dapat dilihat pada gambar 10. Hasil pengujian menunjukan bahwa metode dengan penambahan integral pada sistem mengakibatkan respon sistem menjadi berlebih (overshoot) hingga mencapai $53^{\circ} \mathrm{C}$.

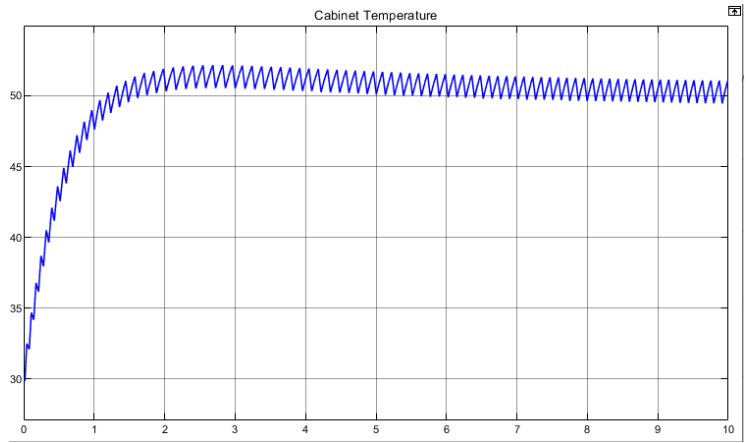

Volume 14, No.1, Januari 2020
Gambar 10. Hasil simulasi dengan menggunakan metode kendali proporsional Integral derivative (PID)

Adapun hasil simulasi dengan menggunakan metode Smart Fuzzy dapat dilihat pada gambar 11. Pada grafik tersebut dapat dilihat bahwa perubahan suhu dari $30^{\circ} \mathrm{C}$ hingga mencapai target suhu sebesar $50^{\circ} \mathrm{C}$ hanya membutuhkan waktu 0.5 menit.

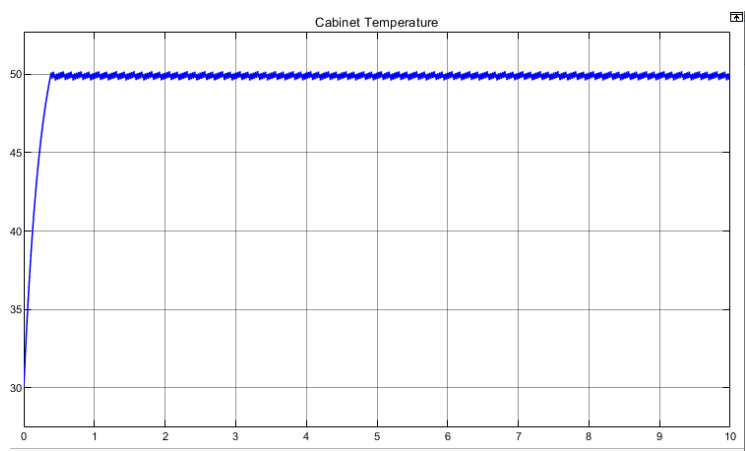

Gambar 11. Hasil pengujian dengan metode Smart Fuzzy

Selain itu, dengan menggunakan metode Smart Fuzzy, suhu yang dikendalikan oleh sistem tidak mengalami overshoot dari target yang diinginkan oleh pengguna. Dari gambar tersebut kita dapat melihat bahwa metode ini mampu menahan suhu tetap terjaga pada suhu target yang telah ditentukan sebelumnya dan hanya mengalami osilasi minor sekitar $\pm 0.2^{\circ} \mathrm{C}$.

\section{KESIMPULAN}

Berdasarkan hasil simulasi yang telah dilakukan, metode Smart Fuzzy menghasilkan performa yang lebih baik dibanding metode konvensional PID dalam mengendalikan suhu ruangan di dalam ruang kabinet pengering. Hal tersebut ditunjukkan dengan keberhasilan metode Smart Fuzzy dalam mencapai nilai suhu yang telah ditentukan sebelumnya dan mampu mempertahankan nilai tersebut. Dalam hal ini suhu yang ditargetkan adalah $50^{\circ} \mathrm{C}$. Dengan metode Smart Fuzzy, suhu dapat bertahan tetap 
di $50^{\circ} \mathrm{C}$ dengan osilasi maksimal $\pm 0.2^{\circ} \mathrm{C}$ sedangkan dengan menggunakan metode PID konvensional, osilasi yang dihasilkan mencapai $\pm 4^{\circ} \mathrm{C}$. Dari hasil ini dapat disimpulkan metode Smart Fuzzy merupakan metode yang tepat untuk digunakan pada alat pengering tanaman obat yang sudah kami rancang.

\section{UCAPAN TERIMA KASIH}

Terima kasih disampaikan kepada Institut Teknologi Sumatera, yang telah memberikan pendanaan untuk penelitian ini melalui skema penelitian Hibah Mandiri.

\section{REFERENSI}

[1] H. M. H Wijayakusuma, "Ramuan Lengkap Herbal Sembuhkan Penyakit", Pustaka Bunda. 2008.

[2] A. Andriati and R. M. T. Wahjudi, "Tingkat penerimaan penggunaan jamu sebagai alternatif penggunaan obat modern pada masyarakat ekonomi rendah-menengah dan atas," Masyarakat, Kebudayaan dan Politik, vol. 29, no. 3, p. 133, Sep. 2016.

[3] H. Heriansyah, S. Istiqphara, and N. Adliani, "DESIGN OF TEMPERATURE CONTROL FOR HERBAL DRYER BASED ON PID CONTROLLER BY UTILIZING RENEWABLE ENERGY SOURCES," Jurnal Ecotipe (Electronic, Control, Telecommunication, Information, and Power Engineering), vol. 6, no. 2, pp. 97-101, Oct. 2019.

[4] A. M. Zungeru, M. Mangwala, J. Chuma, B. Gaebolae, and B. Basutli, "Design and simulation of an automatic room heater control system," Heliyon, vol. 4, no. 6, p. e00655, Jun. 2018.

[5] Y. A. K. Utama and Y. Hari, "Design of PID Disturbance Observer for Temperature Control on Room Heating System," Proceeding of the Electrical Engineering Computer Science and Informatics, vol. 4, no. 1, Oct. 2017.

[6] F. H. Purwanto, E. Utami, and E. Pramono, "Design of server room temperature and humidity control system using fuzzy logic based on microcontroller," 2018 International Conference on Information and Communications Technology (ICOIACT), Mar. 2018.

[7] D. Guanzhou, S. Yue, Q. Jia, M. Xiaoming, and S. Xiaowei, "Research on temperature control system of air conditioning room based on fuzzy control,” 2017 3rd IEEE International Conference on Control Science and Systems Engineering (ICCSSE), Aug. 2017.

[8] L. Ai and H. Pan, "The reactor temperature control based on self-optimizing and selfadjustment fuzzy algorithm," 2011 Eighth International Conference on Fuzzy Systems and Knowledge Discovery (FSKD), Jul. 2011.

[9] L. Wang, H. Zang, and Y. Ning, “The gas water heater control system design based on fuzzy control," 2011 International Conference on Electric Information and Control Engineering, Apr. 2011.

[10]N. I. Septiani, I. Bayusari, Caroline, T. Haiyunnisa, and B. Y. Suprapto, "Optimization of PID control parameters with genetic algorithm plus fuzzy logic in stirred tank heater temperature control process," 2017 International Conference on Electrical Engineering and Computer Science (ICECOS), Aug. 2017. 